\title{
BENCHMARK COMPLIANCE EVALUATION OF THE ROADSIDE DESIGN IN AN URBAN, HIGH-DENSITY AREA
}

\author{
FRANCISCO D. B. ALBUQUERQUE \& DINA M. AWADALLA \\ Department of Civil and Environmental Engineering, United Arab Emirates University, UAE
}

\begin{abstract}
The roadside safety research community has placed a significant amount of effort in developing design and safety guidelines, while focus on the assessment of the proper implementation of these guidelines is lacking. Meanwhile, nearly one-third of all fatal road crashes worldwide involve single-vehicle, run-off-road (SVROR) crashes. The objective of this study is to conduct a roadside design compliance evaluation in an urban, high-density area with regards to a pre-selected benchmark. Visits were made to over 100 SVROR injury-crash locations. Almost all locations were found to be non-compliant. A lack of the minimum recommended clear zone $(\mathrm{CZ})$ provision was the main cause of non-compliance, while $80 \%$ of all locations suffered from barrier misplacement. In conclusion, roadside design guidelines have been poorly implemented in the area studied, and findings indicate that more focus on proper, on-site design implementation is warranted. We are not aware of previous studies that have investigated roadside design compliance in other parts of the world. Hence, we encourage researchers to replicate this study in their respective geographical areas of interest. The authors discuss how the findings of this study may be relevant to researchers, governmental transportation agencies, roadside safety equipment suppliers, practitioners, and decision-makers.

Keywords: road safety, roadside design, compliance, urban area.
\end{abstract}

\section{INTRODUCTION}

\subsection{Background}

Design guidelines have recommended roadside areas to be treated based on five design priorities [1], [2]. The first priority is to, whenever possible, remove the hazard if it is located within the minimum recommended clear zone (CZ) width. According to the 2011 American Association of State Highway and Transportation Officials (AASHTO) Roadside Design Guide (RDG), CZ is defined as the unobstructed, traversable area provided beyond the edge of the through travelled way for the recovery of errant vehicles and should be determined as a function of design speed, average daily traffic (ADT), and roadside terrain topography [1], [2]. The CZ distance values contained in the Abu Dhabi Department of Transport (DOT) RDG are the same as those contained in the 2011 AASHTO RDG, except that the Abu Dhabi DOT RDG does not make recommendations for CZ distance values for design speeds of 90 and $110 \mathrm{~km} / \mathrm{hr}$. In addition, the Abu Dhabi DOT RDG does provide recommended CZ distance values for design speeds higher than $110 \mathrm{~km} / \mathrm{hr}$, whereas the 2011 AASHTO RDG does not. In situations where completely removing the hazard is not possible, design priority \#2 may be pursued, which consists of relocating the hazard farther from the roadway edge such that the hazard may be outside the minimum recommended CZ. Alternatively, the hazard may be re-designed, if possible. Design priority \#3 consists of making the hazard traversable. This can be accomplished in a number of ways. For example, in the case of poles and traffic signs, it has been long shown that the use of breakaway devices, energy absorbing steel columns, and collapsible poles all present the potential to significantly decrease crash severity [3]-[7]. Another example of the application of design priority \#3 would be the 
utilisation of steel grates in the case of culvert openings [8], [9]. If, and only if, none of the first three design priorities are viable options, shielding the hazard with a roadside barrier (i.e., design priority \#4) should be considered. Roadside barriers have been found to contribute to road crash injury causation [8], [10]-[13]. Therefore, barrier installation should be used only when the implementation of the previously cited design priorities is not technically and/or economically feasible. If none of these alternatives are feasible, delineation (i.e., design priority \#5) should be considered, as a minimum [1], [2].

However, while these guidelines have been recommended for many years, there has been no research that has investigated how properly these guidelines have actually been implemented in a dense, urban setting. Instead, much research has been devoted either to study the relationship between SVROR crash frequency/severity and its contributing factors [14]-[19], or to assess the safety performance of roadside hardware based on full-scale crash tests [20], [21].

The first attempt to investigate the characteristics of installed roadside design (i.e., in terms of roadside crash locations and roadside feature configurations) date back to the $1980 \mathrm{~s}$ [22], which was followed by another research published in 1990 [23]. However, these early studies not only were conducted a long time ago (which means they covered areas that may not reflect the urban areas of today's major metropolitan centres), but they also were limited to one specific roadside feature: trees. Later on, a few other studies focused on investigating the relationship between installed urban roadside design and roadside crash frequency. These studies found that the presence of urban roadside furniture, placed to make streets more liveable, tended to significantly decrease the number of roadside crashes [24]-[26]. Another recent study found that streetscape design tending to result in smaller, more enclosed streetscapes contribute to fewer injury or fatal crashes [27].

In sum, previous studies focused on: (a) studying the relationship between single-vehicle, run-off-road crash frequency/severity and its contributing factors [14]-[19], (b) assessing the safety performance of roadside hardware [20], [21], (c) investigating the characteristics of installed roadside design in relation to tree location and configuration [22], [23], and (d) on investigating the relationship between urban street design (i.e., in terms of liveability) and roadside crash frequency or severity [24]-[27]. However, none of these studies identified the level of high-density, urban roadside design compliance to current, state-of-the-art guidelines. Moreover, assessing roadside design compliance should be relevant due to a number of reasons. Firstly, this may provide a feedback to researchers and practitioners in terms of how developed guidelines have actually been implemented on the ground. Secondly, such assessment should shed light into how practical (or impractical) implementation of these guidelines actually may be. For example, roadside design guidelines [1], [2] propose the adoption of $\mathrm{CZ}$ values which have been developed based on a narrow set of road characteristics [28], which may not be reflective of urban areas. Lastly, transportation agencies may prevent costly liability costs by improving roadside design compliance levels.

\subsection{Research objectives}

The objective of this research is to assess the roadside design of an urban, high-density area in terms of its compliance to the selected benchmark. The Abu Dhabi DOT RDG was selected as the benchmark [2]. The 2012 Abu Dhabi DOT RDG is heavily based on the 2011 AASHTO RDG, including its CZ distance policy [1], [2]. 


\section{METHODS}

\subsection{Study area}

The present study conducted an assessment of the roadside design at 119 locations where SVROR-injury crashes had occurred between years 2013 and 2016 within the black, outlined portion of the city of Abu Dhabi, in the United Arab Emirates (UAE), shown in Fig. 1.

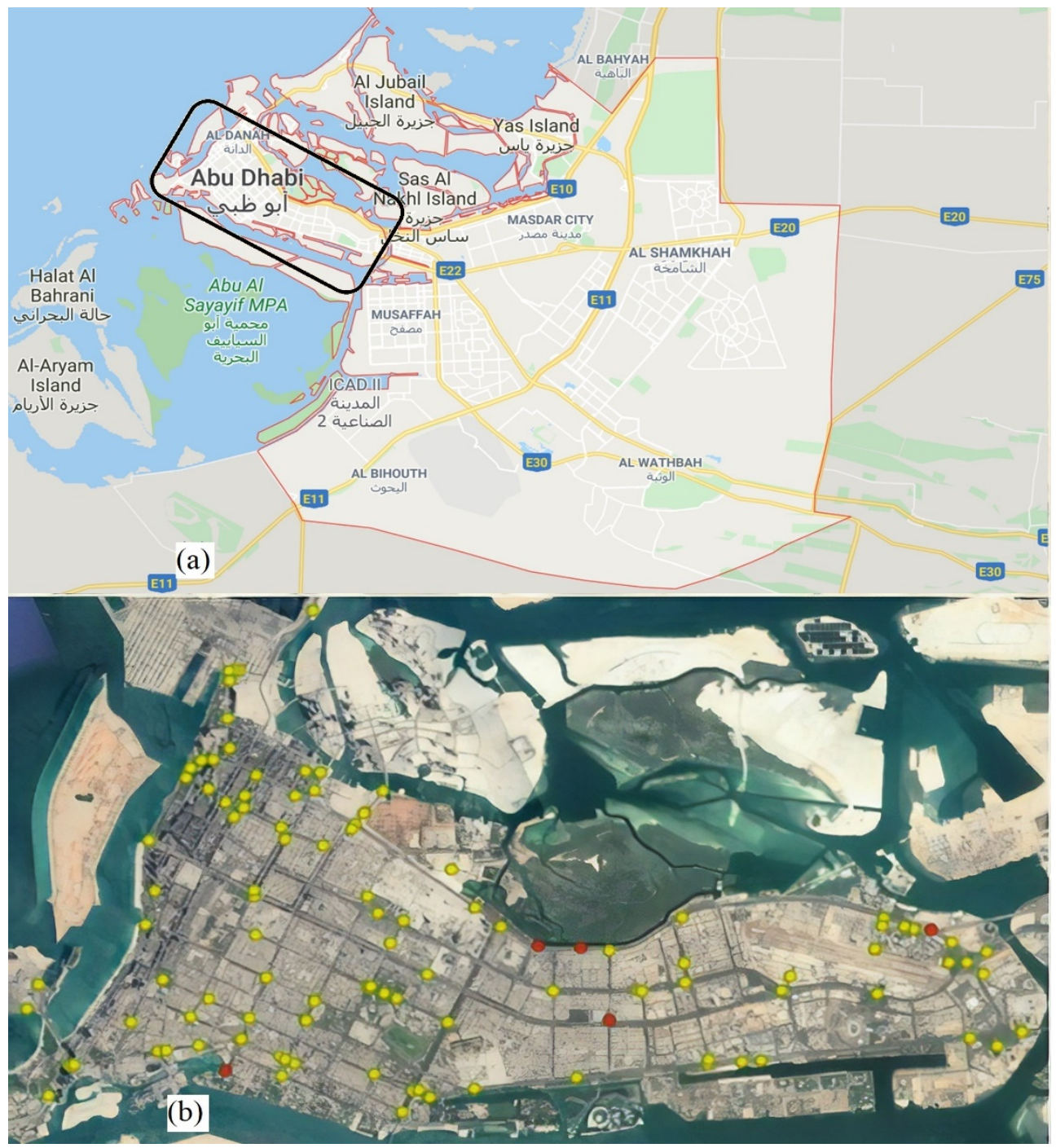

Figure 1: Satellite image for the city of Abu Dhabi and one of its main islands. (a) The city of Abu Dhabi outlined in red and island outlined in black; and (b) Studied SVROR-injury crash locations in yellow and excluded SVROR-Injury crash locations in red. (Source: Google Maps, 2019 [29]; Google Earth, 2019 [30].) 
Fig. 1(a) shows the boundaries of the city of Abu Dhabi in red, as well as those of one of its main islands outlined in black. In Fig. 1(b), the yellow dots represent the 114 SVROR-injury crash locations studied, while the red dots represent the five SVROR-injury crash locations which were excluded from the study because those locations were not accessible due to ongoing construction work taking place during the time the site visits were carried out. The rationale behind focusing on the island outlined in black only was because it is a dense, urban part of the city of Abu Dhabi, making it a suitable area for this study, considering that the objective of this research was to assess roadside design compliance in an urban, high-density environment. The land in this island is mostly used for commercial and residential purposes, translating into a built environment filled with residential villas and apartments, as well as office buildings and commercial properties. The downtown area is located in the north-western part of the island. This is the densest part of the island due to the large number of tall, multi-story buildings in close proximity to each other. In this part of the island, most residents live in apartment buildings; thus, the low number of residential villas. On the other hand, land use and built environment patterns change towards the side of the island closer to the mainland (i.e., the south-eastern corner). That is, not only the number of multi-story buildings per unit of land area decreases, but also the average building height is lower than that in the downtown area. On this side of the island, land use becomes more residential, and the built environment is more occupied by residential villas.

Finally, from a road transportation perspective, the area outlined in black is a very relevant part of the city of Abu Dhabi, demanding its roads to carry larger daily traffic volumes as compared to those observed in Abu Dhabi mainland.

\subsection{Data collection and roadside design problems}

Crash data was provided by the Abu Dhabi Traffic Police. Only injury crashes contained GPS information. Thus, this study was limited to injury crashes. All crashes classified as having involved only one vehicle, as well as falling into the "off-road crash" category, were selected. After excluding 5 sites due to ongoing construction work, a total of 114 cases were selected. Site visits were made to these crash locations. Data collected during site visits included descriptions and measurements of fixed-object type, $\mathrm{CZ}$ distance, hazard-to-roadway lateral offset, curb height, barrier length, barrier-end terminal type, hazard-to-barrier offset, roadside terrain topography, as well as breakaway device and crash cushion use/type. Crash location data collected during visits were compared with roadside design guidelines contained in the Abu Dhabi DOT RDG [2]. Data collected from crash sites was merged with the crash data received from the Abu Dhabi Traffic Police. The Abu Dhabi DOT provided traffic data pertaining to the average daily traffic (ADT) of road locations of interest. ADT information was needed in order for a specific $\mathrm{CZ}$ value to be determined, as per the roadside design guidelines contained in the benchmark [1], [2]. Crash descriptions and diagrams were also reviewed in order to better understand crash dynamics, as well as to extract data on the sequence of crash events and rollover occurrence outcome. Lastly, field, crash, and traffic data were merged into a single, injury-crash dataset.

\subsection{Roadside design guidelines and assessment}

As discussed in Section 1.1, the selected benchmark defines 5 design priorities. In addition to the design priorities, a few other design considerations contained in the benchmark were taken into account to assess whether a roadside design deviated from design guidelines or not. They were: (a) curb height, (b) barrier installation in curb vicinities, (c) roadside barrier 
length of need, (d) barrier crash test level (TL), and (e) barrier working-width requirements [1], [2]. Table 1 provides a few cases of roadside design assessments performed in this study. All 3 cases pertained to locations with flat roadside terrain and ADT volumes of over 6,000. None of the previously described design priorities was properly implemented in any of these cases. Therefore, these designs were found to be non-compliant with the benchmark adopted. However, in the right-most case, the sign was located within the $\mathrm{CZ}$ area but equipped with a breakaway device, thus, this location was found to be compliance with the benchmark adopted.

Table 1: Roadside design assessment examples.

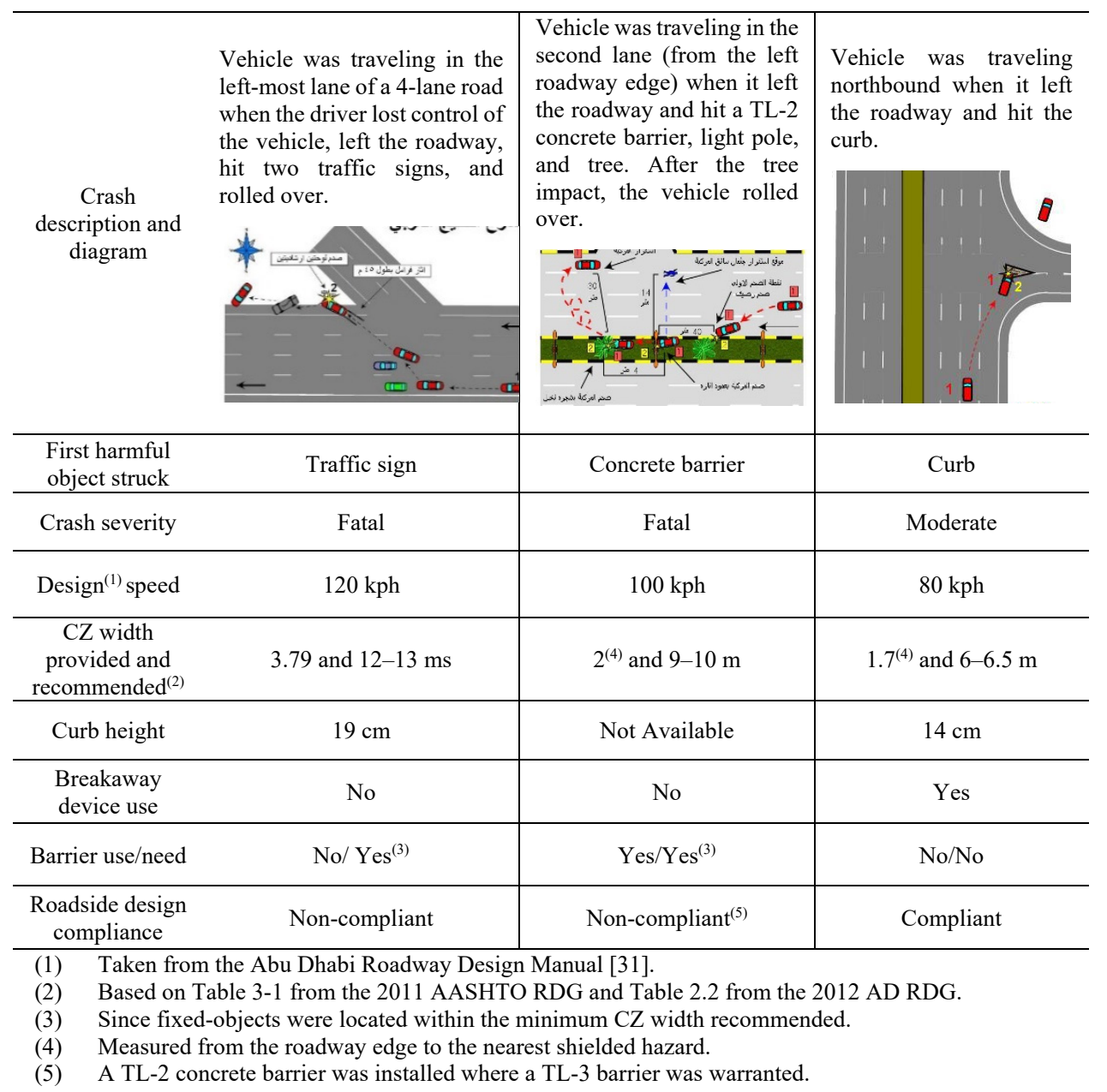

\subsection{Data tabulation}

Data was cross-tabulated showing crash-severity distribution in relation to a number of relevant road-, roadside-, and crash-related variables. Crash severity was classified into two levels: "not severe" and "severe," as shown in Table 2. Injuries reported as "minor" or "moderate" were included in the "not severe" category, while injuries reported as "disabling" 
or "fatal" were included in the "severe" category. Bivariate analyses using cross-tabulation were carried out [32]. Dual percentages are shown for each cross-tabulation category. Percentages in the left-most cells refer to percentages in relation to the column totals, while the percentages in the right-most cells refer to percentages in relation to the row totals. For example, in Table 2, the underlined value 58.3 is a percentage, the product of the ratio between the number of "not severe" crashes that occurred at locations which did not contain deviations from the benchmark (i.e., 7) and the total number of crashes that occurred at locations that did not contain deviations from the benchmark (i.e., 12). Thus, $58.3 \%$ of all crashes that occurred at compliant locations did not involve severe injuries. On the other hand, the italicised percentage value 7.8 is the product of the ratio between the number of "not severe" crashes that occurred at locations that did not contain deviations from the benchmark (i.e., 7) and the total number of "not severe" crashes (i.e., 89). Thus, only 7.8\% of all non-severe crashes occurred at compliant locations.

\section{RESULTS}

A total of 1,573 injury crashes and 119 SVROR-injury crashes occurred on the island between 2013 and 2016. Hence, SVROR-injury crashes accounted for only $7.5 \%$ of all injury crashes. This is a much lower number than that found in previous research conducted in Dubai [14]. This may be explained by the differences in the areas covered. This study focused on a highly dense, urbanised area, whereas the Emirate of Dubai includes areas with varying density levels and road classes.

Table 2 shows that almost $22 \%$ of all SVROR-injury crashes involved severe injuries while a staggering $89.5 \%$ (see number in bold) occurred at locations found to be non-compliant. This indicates that meeting roadside design compliance may be slightly more challenging in a dense, urban area as compared to areas that are not densely populated [33]. This may be attributed to more limited right-of-way (ROW) availability in densely populated areas and may be an indication of the need for research related to the identification of a more practical, minimum-recommended-CZ-distance policy for urban areas. Table 2 also shows that a higher percentage (i.e., 41.7 versus 19.6) of severe crashes occurred at locations in compliance as compared to those not in compliance with the benchmark (see underlined numbers in bold). It is worth stressing that, of course, there is no statistical evidence suggesting that compliant locations tend to produce a higher percentage of severe crashes. Indeed, one cannot draw meaningful conclusions based on a sample size as small as 12 , which is the number of compliant locations. Furthermore, there are a number of other variables that may affect crash severity such as impact speed and seatbelt usage.

Table 2: Crash severity distribution by roadside design compliance.

\begin{tabular}{|c|c|c|c|c|c|c|c|c|}
\hline \multirow{7}{*}{$\begin{array}{c}\text { Crash } \\
\text { severity }\end{array}$} & & & \multicolumn{4}{|c|}{$\begin{array}{c}\text { Roadside design } \\
\text { compliance }\end{array}$} & \multirow{2}{*}{\multicolumn{2}{|c|}{ Sub-totals }} \\
\hline & & & \multirow{2}{*}{\multicolumn{2}{|c|}{ Yes }} & \multirow{2}{*}{\multicolumn{2}{|c|}{ No }} & & \\
\hline & & & & & & & $\#$ & $\%$ \\
\hline & & \# & \multicolumn{2}{|c|}{7} & \multicolumn{2}{|c|}{82} & \multirow{2}{*}{89} & \multirow{2}{*}{78.1} \\
\hline & Not severe & $\%$ & 58.3 & 7.9 & 80.4 & 92.1 & & \\
\hline & \multirow{2}{*}{ severe } & $\#$ & & & \multicolumn{2}{|c|}{20} & \multirow{2}{*}{25} & \multirow{2}{*}{21.9} \\
\hline & & $\%$ & 41.7 & 20.0 & $\underline{19.6}$ & 80.0 & & \\
\hline & \multirow{2}{*}{ Sub-totals } & $\#$ & & & \multicolumn{2}{|c|}{102} & & \\
\hline & & $\%$ & & & \multicolumn{2}{|c|}{89.5} & & \\
\hline
\end{tabular}


Out of the 102 sites (i.e., 114 total sites minus 12 compliant sites) found to be non-compliant, 61 contained poles and traffic signs installed within the minimum recommended $\mathrm{CZ}$ distance. These poles or signs were neither equipped with breakaway devices nor shielded by a barrier. Thirteen sites contained trees, fences, electrical boxes, and walls installed within the minimum recommended $\mathrm{CZ}$ area. These hazards were also not shielded by a barrier. A CZ distance of about $7.8 \mathrm{~m}$ would satisfy the minimum requirements of about $85 \%$ of all locations studied, while about $85 \%$ of the locations studied were actually provided with a $\mathrm{CZ}$ distance of no more than $5.2 \mathrm{~m}$. Six sites contained an insufficient barrier-to-hazard lateral offset, and nine sites contained a TL-2 concrete barrier whereas a TL-3 barrier was warranted. Many of these sites also had curbs that were found to be excessively high. However, only 13 of these locations were classified as non-compliant due to excessively high curbs alone. That is, the convention adopted was that if a crash location contained an excessively high curb but also had a fixed object within the minimum recommended $\mathrm{CZ}$, the roadside design on this location was classified as non-compliant based on the fixed-object presence inside the CZ. Ninety-six out of the 114 studied injury-crash locations were found to contain curbs. There were 76 locations found to have excessively high curbs. Thus, a staggering $79 \%$ of all locations had curb heights higher than $15 \mathrm{~cm}$. In fact, about $35 \%$ of all locations had curbs $20 \mathrm{~cm}$ or higher, and about $20 \%$ of the locations had curb heights of $25 \mathrm{~cm}$ or higher. These numbers are intriguing as the UAE has very light rainfall and, therefore, does not have a storm drainage concern. In addition, these numbers communicate a real safety concern as curbs may be ineffective in redirecting errant vehicles, especially those leaving the road at sharper angles and travelling at higher speeds (i.e., greater than $60 \mathrm{~km} / \mathrm{hr}$ ) [34]. Almost 12\% of all urban SVROR-injury crashes involved a rollover. Out of all rollovers, half were preceded by a curb impact. This is noteworthy, as rollovers, followed by a roadside crash, have been linked to increased crash severity [10].

Table 3 shows that only 13 (see numbers in bold) out of 114 studied injury-crash locations were located on roads that had design speed of $60 \mathrm{~km} / \mathrm{h}$ or lower. This low number may be reflective of the data type (i.e., injury only). That is, injury roadside crashes may be less likely to occur on low speed roads.

Table 3 also shows that 25 out of the 114 studied injury-crash locations were located on roads that had design speeds of $100 \mathrm{~km} / \mathrm{h}$ or higher. This relatively low number may be a reflection of the nature of the area studied, which is an urban, highly populated area. Hence, there are fewer higher-speed roads. On the other hand, $66.7 \%$ (see underlined number) of the locations studied were located on roads with design speed of $80 \mathrm{~km} / \mathrm{h}$. Table 3 also indicates (though no statistical significance has been established) that crash severity on non-compliant road locations with design speeds of no less than $100 \mathrm{~km} / \mathrm{h}$ were higher (see underlined numbers in bold) than crash severities on non-compliant road locations with lower design speeds. This may reinforce the importance of revising the roadside design on higher-speed roads.

Table 4 indicates that trees, poles, barriers and curbs were the first harmful object struck in $69.39 \%$ (see numbers in bold) of all SVROR-injury crashes. Curbs were the first harmful object most often struck, accounting for 24.6 of all SVROR-injury crashes. The fact that the studied area is an urban area (i.e., increasing drivers' exposure to a potential curb impact) partially explains the high percentage associated with curb impacts. In addition, many of the curbs in the studied locations were found to be excessively high, potentially magnifying vehicle deceleration upon impact, as well as causing vehicle instability resulting in greater potential for rollovers [34]. In any case, both high deceleration and increased rollover propensity may have been contributing factors to the appearance of curb impacts in the injury-focused data used. 
Table 3: Crash severity distribution by design speed and roadside design compliance.

\begin{tabular}{|c|c|c|c|c|c|c|c|c|c|c|}
\hline & & & \multicolumn{6}{|c|}{ Legally allowable travelling speed $(\mathrm{km} / \mathrm{h})$} & & \\
\hline & & & \multirow{2}{*}{\multicolumn{2}{|c|}{$\leq 60$}} & \multirow{2}{*}{\multicolumn{2}{|c|}{80}} & \multirow{2}{*}{\multicolumn{2}{|c|}{$\geq 100$}} & \multicolumn{2}{|c|}{ Sub-totals } \\
\hline & & & & & & & & & \# & $\%$ \\
\hline \multirow{6}{*}{$\begin{array}{l}\text { Compliant with } \\
\text { benchmark }\end{array}$} & \multirow{2}{*}{ Not severe } & \# & \multicolumn{2}{|c|}{2} & \multicolumn{2}{|c|}{4} & \multicolumn{2}{|c|}{1} & & \\
\hline & & $\%$ & 100 & 28.6 & 50.0 & 57.1 & 50.0 & 14.3 & 7 & 58.3 \\
\hline & & \# & \multicolumn{2}{|c|}{0} & \multicolumn{2}{|c|}{4} & \multicolumn{2}{|c|}{1} & & \\
\hline & Severe & $\%$ & 0.00 & 0.00 & 50.0 & 80.0 & 50.0 & 20.0 & 5 & 41.7 \\
\hline & \multirow{2}{*}{ Sub-totals } & $\#$ & \multicolumn{2}{|c|}{2} & \multicolumn{2}{|c|}{8} & \multicolumn{2}{|c|}{2} & & \\
\hline & & $\%$ & \multicolumn{2}{|c|}{16.7} & \multicolumn{2}{|c|}{66.7} & \multicolumn{2}{|c|}{16.7} & & \\
\hline \multirow{6}{*}{$\begin{array}{c}\text { Non-compliant } \\
\text { with benchmark }\end{array}$} & \multirow{2}{*}{ Not severe } & \# & \multicolumn{2}{|c|}{9} & \multicolumn{2}{|c|}{57} & \multicolumn{2}{|c|}{16} & & \\
\hline & & $\%$ & 81.8 & 11.0 & 83.8 & 69.5 & 69.6 & 19.5 & 82 & 80.4 \\
\hline & \multirow{2}{*}{ Severe } & \# & \multicolumn{2}{|c|}{2} & \multicolumn{2}{|c|}{11} & \multicolumn{2}{|c|}{7} & & \\
\hline & & $\%$ & 18.2 & 10.0 & 16.2 & 55.0 & 30.4 & 35.0 & 20 & 19.6 \\
\hline & \multirow{2}{*}{ Sub-totals } & $\#$ & \multicolumn{2}{|c|}{11} & \multicolumn{2}{|c|}{68} & \multicolumn{2}{|c|}{23} & & \\
\hline & & $\%$ & \multicolumn{2}{|c|}{10.8} & & & \multicolumn{2}{|c|}{22.5} & & \\
\hline
\end{tabular}

Table 4: Crash severity distribution by the first harmful object struck.

\begin{tabular}{|c|c|c|c|c|c|c|c|c|c|c|c|c|c|c|}
\hline & & & \multicolumn{12}{|c|}{ First harmful object struck } \\
\hline & & & \multirow{2}{*}{\multicolumn{2}{|c|}{ Tree }} & \multirow{2}{*}{\multicolumn{2}{|c|}{ Pole }} & \multirow{2}{*}{\multicolumn{2}{|c|}{ Barrier }} & \multirow{2}{*}{\multicolumn{2}{|c|}{ Curb }} & \multirow{2}{*}{\multicolumn{2}{|c|}{ Others }} & \multicolumn{2}{|c|}{ Sub-totals } \\
\hline & & & & & & & & & & & & & \# & $\%$ \\
\hline \multirow{4}{*}{$\begin{array}{c}\text { Crash } \\
\text { sever- } \\
\text { ity }\end{array}$} & \multirow{2}{*}{$\begin{array}{c}\text { Not } \\
\text { severe }\end{array}$} & $\#$ & & & \multicolumn{2}{|c|}{19} & \multicolumn{2}{|c|}{14} & \multicolumn{2}{|c|}{23} & \multicolumn{2}{|c|}{27} & \multirow{2}{*}{89} & \multirow{2}{*}{78.1} \\
\hline & & $\%$ & 66.7 & 6.74 & 82.6 & 21.4 & 73.7 & 15.7 & 82.1 & 25.8 & 77.1 & 30.3 & & \\
\hline & \multirow{2}{*}{ Severe } & \# & & & \multicolumn{2}{|c|}{4} & \multicolumn{2}{|c|}{5} & \multicolumn{2}{|c|}{5} & \multicolumn{2}{|c|}{8} & \multirow{2}{*}{25} & \multirow{2}{*}{21.9} \\
\hline & & $\%$ & $\underline{33.3}$ & 12.0 & 17.4 & 16.0 & 26.3 & 20.0 & 17.9 & 20.0 & 22.9 & 32.0 & & \\
\hline & \multirow{2}{*}{$\begin{array}{l}\text { Sub- } \\
\text { totals }\end{array}$} & $\#$ & & & \multicolumn{2}{|c|}{23} & \multicolumn{2}{|c|}{19} & \multicolumn{2}{|c|}{28} & \multicolumn{2}{|c|}{35} & & \\
\hline & & $\%$ & & & \multicolumn{2}{|c|}{20.2} & \multicolumn{2}{|c|}{16.7} & \multicolumn{2}{|c|}{24.6} & \multicolumn{2}{|c|}{30.7} & & \\
\hline
\end{tabular}

Table 4 also shows that while only $17.4 \%$ (see bod underlined number) of all pole crashes involved severe injuries, a striking $95 \%$ of all pole-injury crashes occurred at locations containing design not in line with the benchmark. This can be attributed to the fact that the majority of poles located within the minimum $\mathrm{CZ}$ distance recommended by the benchmark were not equipped with breakaway devices or any other sort of energy-absorbing mechanism, and/or were not shielded. Table 4 shows that tree crashes proved to be the most severe crashes, as $33.3 \%$ (see underlined number) of all tree encounters resulted in severe injuries. All tree locations were classified as non-compliant, except for only one location. It is also relevant to point out that all tree crashes involved palm trees, which may be considered unforgiving, rigid roadside-object hazards. The "others" category involved crashes with objects such as traffic signs, signal poles, fences, and walls. Lastly, Table 4 shows that $26.3 \%$ (see italicized number) of all crashes involving a roadside barrier resulted in a severe crash outcome. This reinforces the fact that barriers are also hazards [8], [10], [11]. Therefore, design priorities preceding priority \#4 should always be sought whenever possible.

Table 5 shows the distribution of crash site locations by crash severity, barrier usage, barrier requirements, and barrier compliance status. As can be seen, 64.9\% (see underlined number) of all SVROR-injury crashes occurred at locations where a barrier was not installed where it should have been. These locations mostly included those where fixed-object hazards, such as unforgiving poles and trees, were within the minimum recommended $\mathrm{CZ}$ distance. Table 5 also shows that $16.7 \%$ (see numbers in bold) of the locations had a roadside barrier installed where one was warranted, but 15 out of the 19 roadside designs contained in these locations were classified as non-compliant. Six out of these 15 designs involved an insufficient barrier-to-hazard lateral offset. This lateral offset is the distance from the back of 
the barrier to the front face of the hazard, which should be provided in order to accommodate barrier deflection as well as zone-of-intrusion (ZOI) upon a vehicle impact. ZOI can be defined as the area that should be provided behind a barrier and beyond its dynamic deflection distance. ZOI values may vary widely depending on a number of variables such as barrier TL, type, and height. Finally, out of the 15 barrier locations classified as non-compliant, nine cases involved a TL-2 barrier where a TL-3 was warranted. Hence, these numbers suggest that greater emphasis on proper barrier selection and layout may be warranted. Finally, Table 5 shows that $18.4 \%$ (see double underlined number) of the locations did not have a roadside barrier installed when one was not required. Thus, $78.1 \%$ (i.e., 13.2 plus 64.9 ) of all crash sites investigated did not meet roadside design guidelines for barrier placement. A total of $18 \%$ (i.e., 15 out of 89 ) of these sites involved severe crashes.

Table 5: Crash severity distribution by barrier used.

\begin{tabular}{|c|c|c|c|c|c|c|c|c|c|c|c|c|}
\hline & \multicolumn{12}{|c|}{ Barrier use } \\
\hline & & & \multirow{2}{*}{\multicolumn{2}{|c|}{$\mathrm{U}, \mathrm{R}, \mathrm{C}$}} & \multirow{2}{*}{\multicolumn{2}{|c|}{$\mathrm{U}, \mathrm{R}, \mathrm{NC}$}} & \multirow{2}{*}{\multicolumn{2}{|c|}{$\mathrm{NU}, \mathrm{R}, \mathrm{NC}$}} & \multirow{2}{*}{\multicolumn{2}{|c|}{ NU, NR, C }} & \multicolumn{2}{|c|}{ Sub-totals } \\
\hline & & & & & & & & & & & $\#$ & $\%$ \\
\hline \multirow{4}{*}{$\begin{array}{c}\text { Crash } \\
\text { severity }\end{array}$} & \multirow{2}{*}{$\begin{array}{c}\text { Not } \\
\text { severe }\end{array}$} & $\#$ & \multicolumn{2}{|c|}{2} & \multicolumn{2}{|c|}{12} & \multicolumn{2}{|c|}{62} & \multicolumn{2}{|c|}{13} & \multirow{2}{*}{89} & \multirow{2}{*}{78.1} \\
\hline & & $\%$ & 50 & 2.25 & 80.0 & 13.5 & 83.8 & 69.7 & 61.9 & 14.6 & & \\
\hline & \multirow{2}{*}{ Severe } & \# & \multicolumn{2}{|c|}{2} & \multicolumn{2}{|c|}{3} & \multicolumn{2}{|c|}{12} & \multicolumn{2}{|c|}{8} & \multirow{2}{*}{25} & \multirow{2}{*}{21.9} \\
\hline & & $\%$ & 50.0 & 8.0 & 20.0 & 12.0 & 16.2 & 48.0 & 38.1 & 32.0 & & \\
\hline & \multirow{2}{*}{$\begin{array}{c}\text { Sub- } \\
\text { totals }\end{array}$} & $\#$ & \multicolumn{2}{|c|}{4} & \multicolumn{2}{|c|}{15} & \multicolumn{2}{|c|}{74} & \multicolumn{2}{|c|}{21} & & \\
\hline & & $\%$ & \multicolumn{2}{|c|}{3.5} & \multicolumn{2}{|c|}{13.2} & \multicolumn{2}{|c|}{64.9} & \multicolumn{2}{|c|}{18.4} & & \\
\hline
\end{tabular}

U: Used barrier, NU: Not used barrier; R: Required, NR: Not required.

$\mathrm{C}$ : Compliant with the benchmark; NC: Non-compliant with the benchmark.

\section{DISCUSSION}

This research study may be relevant to:

\subsection{Researchers}

This study may enable researchers to identify research gaps needing to be filled as well as to formulate roadside-safety/design-related research questions worth answering. For example, researchers may want to investigate whether increased roadside compliance levels (e.g., proper implementation of crash-tested and approved roadside hardware) translates into significantly lower crash severity in the real world. Such an assessment would require in-service safety evaluations. Some might argue that it is intuitive that in-service safety performance would be improved on locations meeting roadside design compliance. However, previous research has shown that conclusions derived from fully-controlled experimental testing do not necessarily always hold true in the real world [10]. Furthermore, urban streets with more liveable streets (i.e., shorter CZ distances) have found to be safer [24]-[26]. The findings from these later roadside safety studies conducted in urban streets, along with the fact that the present study revealed that almost all studied urban crash locations did not meet the minimum recommended $\mathrm{CZ}$ distance requirements, suggest that $\mathrm{CZ}$ values recommended by AASHTO, as well as those recommended by Abu Dhabi DOT, should be re-assessed when it comes to urban street applications. The AASHTO CZ values find their roots in a 1966 study [28] which was conducted in rural areas, focused on medians, had its share of limitations, and was later confronted [35]. Such an assessment could be performed based on in-service crash severity reduction effectiveness. Hence, if researchers find that matching $\mathrm{CZ}$ distances to those recommended by the benchmark does not translate into significantly lower crash injury levels, researchers may consider recommending shorter $\mathrm{CZ}$ 
distance values which may be more practical to adopt in the urban street context. Even though previous studies [24]-[26] have suggested that shorter clear zones in urban streets may be associated with lower crash severity, researchers are yet to develop CZ guidelines based on identified optimal $\mathrm{CZ}$ values for urban applications.

\subsection{Practitioners and road safety equipment suppliers}

The findings of this paper can provide practitioners with valuable feedback, allowing them to gauge the extent to which they have actually followed guidelines that, in theory, they must adhere to. Often times, road designers tend to focus on roadway geometrics and pavement design, while roadside design may be overlooked. However, this study indicates that practitioners are encouraged to place a greater focus on roadside design, as over $90 \%$ of all crash sites investigated in this study were classified as non-compliant.

This study found that poles were the second first harmful object most often struck, while none of these poles was found to be equipped with breakaway devices or any sort of energy-absorbing mechanism. Thus, suppliers may use these findings to educate and encourage clients to replace existing poles with forgiving ones, which they may want to market.

Suppliers may also make use of the findings from this study to encourage their clients to properly install more safety devices such as crash cushions and non-rigid barriers (e.g., w-beam guardrails and cable barriers), especially on higher-posted-speed-limit roads. This study found that $65 \%$ of the crash sites investigated warranted a barrier but one was not installed, while $80 \%$ (see Table 5) of all crash sites investigated did not meet roadside design guidelines for barrier placement. This is relevant considering that past research has shown that the odds of fatal injuries occurring in pole and tree crashes are significantly higher than the odds of fatal injuries occurring in guardrail crashes [36].

\subsection{Governmental transportation agencies and decision makers}

This study may be instrumental to governmental transportation agencies in order to understand what the main causes for non-compliance were. Then, these agencies will be in a better position to decide (for the sake of increased compliance levels) whether the causes for non-compliance should be treated or design guidelines should be modified in the first place. Having a compliant design is important for these agencies since public money can be saved by avoiding potential liability-related costs.

Decision makers are encouraged to invest heavily in road safety audits across road networks in order to monitor proper, on-site design implementation of roadside guidelines. Road safety audits have been found to be cost-effective safety procedures that have the potential to be a proactive, rather than a reactive measure [37]. Decision makers may also make use of this study's findings to understand the areas where their capital resources should be allocated. In the area studied, higher-design-speed roads, as well as tree, pole, and curb locations are all places that might warrant receiving capital deployment, if roadside design compliance is to be improved.

\section{CONCLUSIONS}

Previous research studies focused on: (a) studying the relationship between SVROR crash frequency/severity and its contributing factors [14]-[19], (b) assessing the safety performance of roadside hardware [20], [21], (c) investigating the characteristics of installed roadside design in relation to tree location and configuration [22], and (d) on investigating 
the relationship between urban street design (i.e., in terms of liveability) and roadside crash frequency or severity [11], [14]-[16]. However, none of these studies identified the level of urban roadside design compliance to current, state-of-the-art guidelines [1], [2].

The objective of this research is to assess the roadside design of an urban, high-density area in terms of its compliance to the selected benchmark defined in section 1.2. Therefore, it was not the primary objective of this study to investigate the relationship between compliance levels and crash severity, though crash severity data has been displayed throughout this text. It is known that such an investigation would require a larger sample size to enable researchers to draw statistical evidence while controlling for potential crash-severity-contributing factors. Nevertheless, this is a unique research study in the sense that the authors are unaware of any other previous study done addressing this topic in any other part of the world.

This research reveals that the roadside design in the area studied significantly deviates from the benchmark, defined in section 1.2 [1], [2]. Thus, significant design modification is required if it is to match design standards recommended by the international roadside safety community. It is important to stress that land use characteristics and built environment patterns may have contributed to the currently installed roadside design's significant deviation from the benchmark. That is, because of its highly dense, urbanized character, a large portion of the island may have roads with extremely limited $\mathrm{CZ}$ areas.

While the development of life-saving guidelines is important, this paper shows that researchers and practitioners are encouraged to place more focus on the proper, on-site design implementation of these guidelines, and/or the revision of the guidelines under an urban-application viewpoint.

\section{ACKNOWLEDGEMENTS}

The authors would like to thank the United Arab Emirates University for funding this research effort under grant number 31N262. The authors would also like to thank the staff at the Abu Dhabi Traffic Police as well as the staff at the Abu Dhabi DOT.

\section{REFERENCES}

[1] American Association of State Highway and Transportation Officials (AASHTO), Roadside Design Guide, 4th ed., American Association of State Highway and Transportation Officials: Washington, DC, 2011.

[2] Abu Dhabi Department of Transport, Roadside Design Guide, 2nd ed., Abu Dhabi Department of Transport: Abu Dhabi, 2012.

[3] British Standards Institution (BSI), Passive Safety of Support Structures for Road Equipment. Requirements Classification and Test Methods, British Standards Institution: UK, 2007.

[4] Edwards, T.C., Concepts and design recommendations for safer luminaire supports. Highway Research Record, Report No. 259, National Research Council: USA, 1969.

[5] Pfeifer, B.G., Holloway, J.C., Faller, R.K., Post, E.R. \& Christensen, D.L., Full-scale crash tests on a luminaire support 4-bolt slipbase design. Transportation Research Record, 1367, pp. 13-22, 1992.

[6] Stoughton, R.L., Abghari, A., Dusel, J.P., Hedgecock, J.L. \& Glauz, D.L., Vehicle impact testing of lightweight lighting standards. Transportation Research Record, 1233, pp. 51-64, 1989.

[7] Williams, G.L., Kennedy, J.V., Carroll, J.A. \& Beesley, R., The use of passively safe signposts and lighting columns. Report No. PPR 342, Transport Research Laboratory, 2008. 
[8] Albuquerque, F.D.B., Sicking, D.L., Faller, R.K. \& Lechtenberg, K.A., Evaluating the cost-effectiveness of roadside culvert treatments. Journal of Transportation Engineering, 137(12), pp. 918-925, 2012.

https://doi.org/10.1061/(ASCE)TE.1943-5436.0000266.

[9] Polivka, K.A., Sicking, D.L., Reid, J.D., Bielenberg, B.W., Faller, R.K. \& Rohde, J.R., Performance evaluation of safety grates for cross-drainage culverts. Report No. TRP03-196-08, Midwest Roadside Safety Facility, University of Nebraska-Lincoln: Lincoln, Nebraska, 2008.

[10] Albuquerque, F.D.B. \& Sicking, D.L., In-Service safety performance evaluation of roadside concrete barriers. Journal of Transportation Safety and Security, 5(2), pp. 148-164, 2013. https://doi.org/10.1080/19439962.2012.715618.

[11] Albuquerque, F.D.B., Sicking, D.L. \& Stolle, C., Optimal guardrail runout lengths for freeways. Journal of Transportation Safety and Security, 9(4), pp. 403-418, 2016. https://doi.org/10.1080/19439962.2016.1237599.

[12] Daniello, A. \& Gabler, H.C., Effect of barrier type on injury severity in motorcycleto-barrier collisions in North Carolina, Texas, and New Jersey. Transportation Research Record, 2262, pp. 144-151, 2011. https://doi.org/10.3141/2262-14.

[13] Sicking, D., Albuquerque, F.D.B., Lechtenberg, K.A. \& Stolle, C., Guidelines for implementation of cable median barrier. Transportation Research Record, 2120, pp. 82-90, 2009. https://doi.org/10.3141/2120-09.

[14] Al-Dah, M.K., Causes and consequences of road traffic crashes in Dubai. PhD dissertation, Loughborough University, 2010.

[15] Liu, C. \& Subramanian, R., Factors related to fatal single-vehicle run-off-road crashes. Report No. DOT HS 811 232, U.S. Department of Transportation and National Highway Traffic Safety Administration: Washington, DC, 2009.

[16] Palamara, P., Broughton, M. \& Fraser, M., An investigation of urban area run off road crashes in Western Australia 2005-2009. Report No. RR 10-005, Curtin-Monash Accident Research Centre: Bentley, Australia, 2013.

[17] Shawky, M., Hassan, H.M., Garib, A. \& Al-Harthei, H.A., Examining the factors affecting the severity of run-off-road crashes in Abu Dhabi. Canadian Journal of Civil Engineering, 43(2), pp. 132-138, 2016. https://doi.org/10.1139/cjce-2014-0393.

[18] Somchainuck, O., Taneerananon, P. \& Jaritngam, S., An in-depth investigation of roadside crashes on Thai national highway. Engineering Journal, 17(2), pp. 63-74, 2012. https://doi.org/10.4186/ej.2013.17.2.63.

[19] Van Petegem, J.H. \& Wegman, F., Analyzing road design risk factors for run-off-road crashes in the Netherlands with crash prediction models. Journal of Safety Research, 49, pp. 121-127, 2014. https://doi.org/10.1016/j.jsr.2014.03.003.

[20] AASHTO, Manual for Assessing Safety Hardware, American Association of State Highway and Transportation Officials: Washington, DC, 2009.

[21] Ross, H.E.J.R., Sicking, D.L., Zimmer, R.A. \& Michie, J.D., Recommended procedures for the safety performance evaluation of highway features. NCHRP Report 350, National Research Council: Washington, DC, 1993.

[22] Zeigler, A.J., Guide to the management of roadside trees. Report No.: FHWA-IP-8617, Michigan Department of Transportation: Lansing, USA, 1986.

[23] Turner, D.S. \& Mansfield, E.R., Urban trees and roadside safety. Journal of Transportation Engineering, 116(1), 1990. https://doi.org/10.1061/(ASCE)0733-947X(1990)116:1(90).

[24] Dumbaugh, E. \& Gattis, J.L., Safe streets, livable streets. Journal of the American Planning Association, 71(3), pp. 283-300, 2005. 
https://doi.org/10.1080/01944360508976699.

[25] Marshall, W.E., Coppola, N. \& Golombek, Y., Urban clear zones, street trees, and road safety. Research in Transportation Business and Management, 29, pp. 136-143, 2018. https://doi.org/10.1016/j.rtbm.2018.09.003.

[26] Naderi, J.R., Landscape design in clear zone: Effect of landscape variables on pedestrian health and driver safety. Transportation Research Record, 1851, pp. 119130, 2003. https://doi.org/10.3141/1851-12.

[27] Harvey, C. \& Aultman-Hall, L., Urban streetscape design and crash severity. Transportation Research Record, 2500, pp. 1-8, 2015. https://doi.org/10.3141/2500-01.

[28] Hutchinson, J.W. \& Kennedy, T.W., Medians of divided highways-frequency and nature of vehicle encroachments. Report No. 487, University of Illinois: Chicago, USA, 1966.

[29] Google Maps, Abu Dhabi, 2019. www.google.com/maps/place/Abu+Dhabi/ @ $24.3865729,54.2784033,10 \mathrm{z} / \mathrm{data}=! 3 \mathrm{~m} 1$ ! 4b1!4m5!3m4!1s0x3e5e440f723ef2b9:0x c7cc2e9341971108!8m2!3d24.453884!4d54.3773438. Accessed on: 14 Oct. 2019.

[30] Google Earth, Abu Dhabi, 2019. https://earth.google.com/web/@24.36163916, 54.68068516,8.52037342a,111865.24963634d,35y,0.00187375h,0.38401801t,0r/data=CkwaShJECiUweDNINWU0NDBmNzIzZWYyYjk6MHhjN2NjMmU5Mz QxOTcxMTA4GXst6L0xdDhAIZcsOM1MMEtAKglBYnUgRGhhYmkYAiAB. Accessed on: 14 Apr. 2019.

[31] Abu Dhabi City Municipality, Roadway Design Manual, 2nd ed., Abu Dhabi Department of Municipal Affairs: Abu Dhabi, 2014.

[32] Agresti, A., Categorical Data Analysis, 3rd ed., John Wiley and Sons: New Jersey, 2012.

[33] Albuquerque, F.D.B. \& Awadalla, D.M., Roadside design assessment in an urban, low-density environment in the Gulf Cooperation Council region. Traffic Injury Prevention, 20(4), pp. 436-441, 2019. https://doi.org/10.1080/15389588.2019.1602770.

[34] Plaxico, C.A. et al., Recommended guidelines for curb and curb-barrier installations. Report No. 537, National Cooperative Highway Research Program (NCHRP): Washington DC, 2005.

[35] Cooper, P.J., Analysis of Roadside Encroachment Data From Five Provinces and its Application to an Off-Road Vehicle Trajectory Model, British Columbia Research Council: Vancouver, 1981.

[36] Albuquerque, F.D.B. \& Awadalla D.M., Roadside fixed-object collisions, barrier performance, and fatal injuries in single-vehicle, run-off-road crashes. Safety, 6(2), p. 27, 2020. https://doi.org/10.3390/safety6020027.

[37] Elvis, R., Høye, A., Vaa, T. \& Sørensen, The Handbook of Road Safety Measures, 2nd ed., Emerald Group: Bingley, 2009. 